\title{
Hydrocephalus due to Galen vein aneurysm associated with arteriovenous malformation in an adult patient
}

Bahar Atasoy, Rasul Sharifov, Hafize Otçu, Alpay Alkan

Department of Radiology, Bezmialem Vakıf University, Istanbul, Turkey

Submitted: 20 June 2016

Accepted: 20 June 2016

Arch Med Sci Civil Dis 2016; 1: e55-e57

DOI: 10.5114/amscd.2016.60862

Copyright @ 2016 Termedia \& Banach

Great Galen vein aneurysms are rare intracranial vascular malformations which are especially seen in the neonatal period. They comprise a diverse group of vascular anomalies, and different classifications are described in the literature [1]. Hemodynamically, Galen vein aneurysms are classified into two types. One type comprises the true vein of Galen malformations (VOGMs), which constitute $1 \%$ of all intracranial vascular malformations and most commonly affect the neonatal population, in whom congestive heart failure is the primary presentation. These lesions are characterized by the presence of an aneurysmally dilated deep venous structure, fed by abnormal arteriovenous communications. The second classification is Galen vein aneurysmatic dilatation due to high flow parenchymal arteriovenous malformation (AVM), which produces engorgement and dilatation of the Galen vein. We report a rare case of Galen vein aneurysm caused by AVM leading to obstruction at the cerebral aqueduct.

A 57-year-old man with metastatic lung cancer presented to the neurology department with complaints of fatigue and insomnia. The physical examination revealed mild motor weakness at the left arm. The other neurological tests were normal. The blood test results showed mild anemia due to chronic disease, increased low-density lipoproteins (LDH) and decreased levels of 25-hydroxy vitamin D. Brain magnetic resonance imaging (MRI) was performed (1.5 Tesla, Siemens, Avanto, Erlangen, Germany) and revealed multiple metastatic lesions in cerebral and cerebellar hemispheres with heterogeneous contrast enhancement and diffuse vasogenic edema around the lesions on T2 weighted images (Figure $1 \mathrm{~A}$ ). The arteriovenous malformation was visualized at the deep medial part of the left temporo-occipital lobe. The nidus was seen at the central part of the AVM after contrast administration (Figure $1 \mathrm{~B}$ ). The arterial feeder was the posterior cerebellar artery, and the venous drainage was supplied by the internal cerebral vein, which drains into the Galen vein. The Galen vein was observed to be aneurysmatic due to increased blood flow and probably due to obstruction. The aneurysmatic Galen vein caused obstruction at the level of the cerebral aqueduct, leading to noncommunicating hydrocephalus (Figures $2 \mathrm{~A}, \mathrm{~B}$ ).

The vein of Galen, also named the great cerebral vein, is a venous structure formed by the two internal cerebral veins and the basal veins of Rosenthal and lies at the quadrigeminal cistern. The VOGMs are very rare congenital vascular malformations constituting $1 \%$ of all intracranial vascular malformations at any age, but it rises to $30 \%$ in the neonatal period. They result from abnormal connections between the choroidal

\author{
Corresponding author: \\ Dr Bahar Atasoy \\ Department of Radiology \\ Bezmialem Vakıf University \\ Vatan Caddesi, Fatih \\ Adnan Menderes Bulvarı \\ 42017 Istanbul, Turkey \\ Phone: +90 02124531700 \\ E-mail: bahar_atasoy@ \\ hotmail.com
}


vessels and the median prosencephalic vein - the precursor of the Galen vein. Secondary Galen vein aneurysms are hemodynamically associated with a parenchymal AVM and present in childhood and adulthood with the features of hydrocephalus, seizures and focal neurologic deficits. Galen vein aneurysms are frequently associated with an AVM located at the posterior part of the third ventricle and less commonly in the quadrigeminal plate [1, 2]. In the literature, Galen vein aneurysms have been classified into three groups by several authors: 1) Galen vein aneurysms which are fed directly by branches of the carotid/vertebrobasilar circulations, especially by the posterior vertebral arteries; 2) aneurysms associated with AVMs lo- cated in the posterior thalamus or quadrigeminal plate; 3) Galen vein aneurysms composed of malformations of both circulation patterns. The drainage into the deep venous system due to this abnormal arteriovenous fistula formation causes engorgement and dilatation of the Galen vein. Mayberg et al. [2] described this pathogenesis by the direct arteriovenous fistula into the aneurysm of the Galen vein, and probably there is a communication of the lesions between fistulas and the AVM with the deep venous drainage [2]. Studies show that in half of the cases of fistula or AVMs associated with Galen vein aneurysm, the arterial supply is derived from one or both posterior cerebral arteries, as in our case [1, 3, 4]. Occasionally,
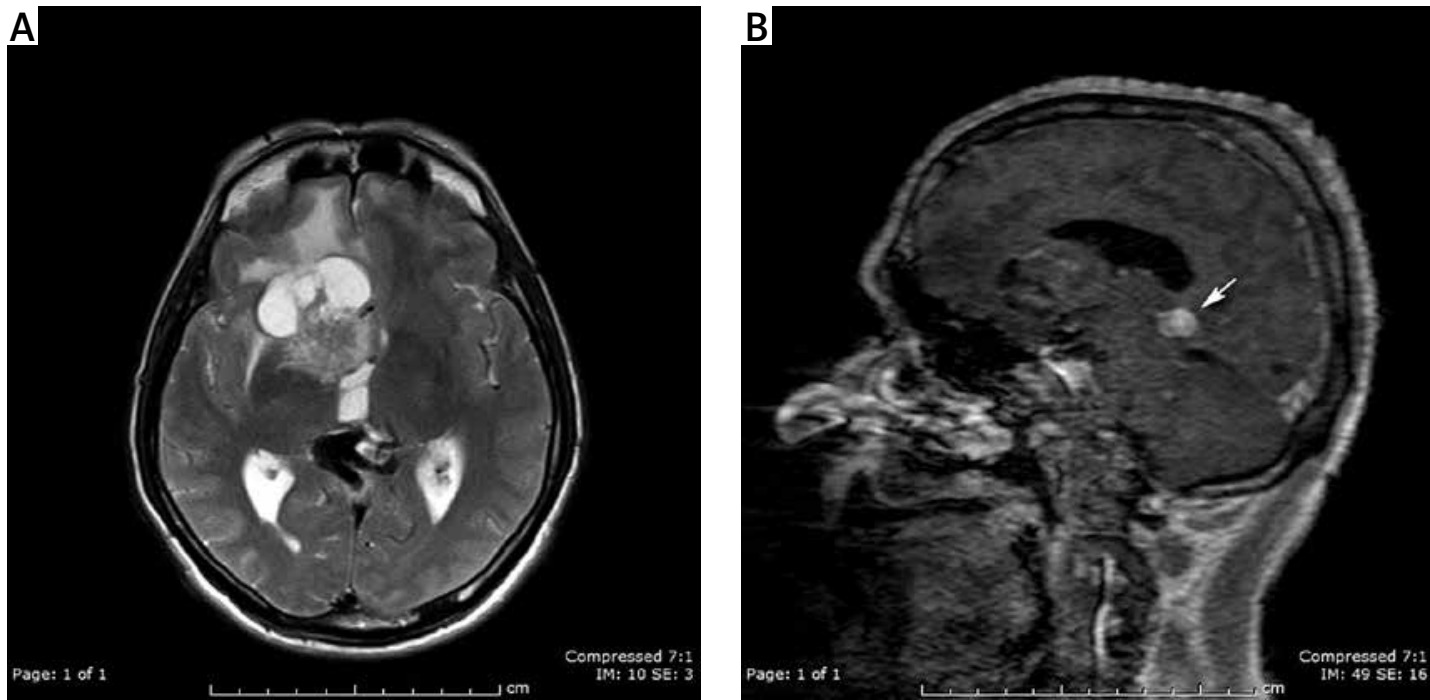

Figure 1. A - T2W axial image shows the dilatation of the thalamoperforating arteries which are the arterial suppliers of the AVM. Metastatic lesions with perilesional vasogenic edema are present at the cerebral hemisphere. B - T1W sagittal image after contrast administration shows the nidus at the central part of the AVM (arrow)
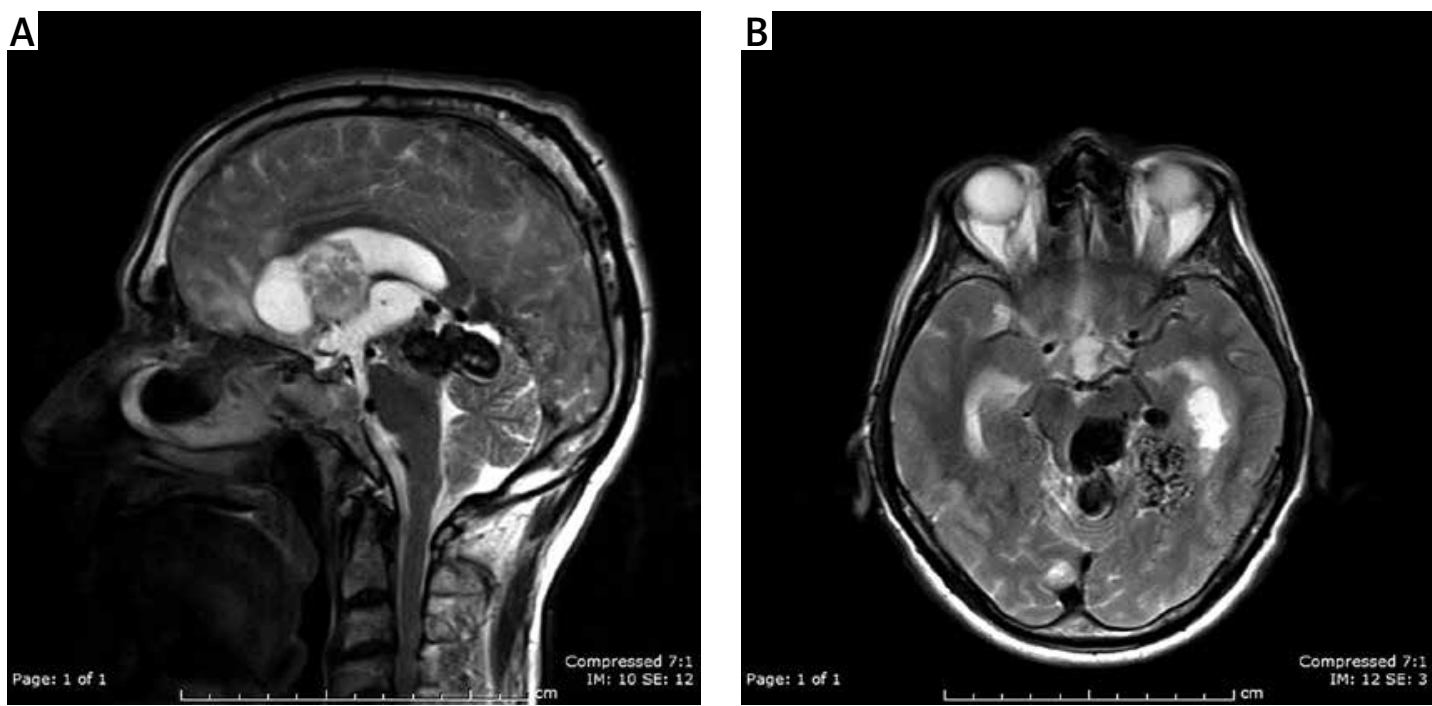

Figure 2. A - T2W sagittal image shows aneurysmatic dilatation of the Galen vein causing obstruction of the cerebral aqueduct. The lateral ventricles and the third ventricle are dilated. Metastatic lesions are present in the cerebral hemisphere. B - T2W axial images shows the AVM located at the posterior part of the third ventricle draining into the Galen vein. The arterial feeder of the AVM is the posterior cerebral artery 
the arterial feeders are branches of the anterior cerebral, anterior choroidal or superior cerebellar arteries. There are reported cases of AVMs and associated Galen vein aneurysms, and hydrocephalus was described as the most commonly presenting symptom in children and adults [4-7]. One reported case showed that sinus thrombosis can precede the development of the dural AVM and the Galen vein aneurysm. In our case no sinus thrombosis was detected [2]. However, there were multiple brain metastases due to lung adenocarcinoma. Galen vein aneurysms due to AVMs are being detected with increasing frequency because of the new improved diagnostic techniques and awareness of this clinical entity. During the clinical follow-up of the patient with a parenchymal AVM located at the posterior part of the third ventricle, dilatation of the Galen vein should be radiologically suspected, and if it exists it should be reported. In the following MRI imaging, hydrocephaly formation due to cerebral aqueduct obstruction should be taken into consideration in cases with Galen vein aneurysmatic dilatation.

\section{Conflict of interest}

The authors declare no conflict of interest.

\section{References}

1. Martelli A, Scotti G, Harwood-Nash DC, et al. Aneurysms of the vein of Galen in children: CT and angiographic correlations. Neuroradiology 1980; 20: 123-33.

2. Mayberg MR, Zimmerman C. Vein of Galen aneurysm associated with dural AVM and straight sinus thrombosis. Case report. J Neurosurg 1988; 68: 288-91.

3. Amacher AL, Shillito J Jr. The syndromes and surgical treatment of aneurysms of the great vein of Galen. J Neurosurg 1973; 39: 89-98.

4. Hoffman HJ, Chuang S, Hendrick EB, et al. Aneurysms of the vein of Galen. Experience at the Hospital for Sick Children, Toronto. J Neurosurg 1982; 57: 316-22.

5. Seidenwurm D, Berenstein A, Hyman A, et al. Vein of Galen malformation: correlation of clinical presentation, arteriography, and MR imaging. AJNR 1991; 12: 347-54.

6. Recinos PF, Rahmathulla G, Monica Pearl M, et al. Vein of Galen malformations: epidemiology, clinical presentations, management. Neurosurg Clin N Am 2012; 23: 165-77.

7. Levrier O, Gailloud PH, Souei M, Manera L, Brunel H, Raybaud C. Normal galenic drainage of the deep cerebral venous system in two cases of vein of Galen aneurysmal malformation. Childs Nerv Syst 2004; 20: 91-7. 